\title{
Vascular Health is Associated with Amyloid- $\beta$ in Cognitively Normal Older Adults
}

\author{
Yumei Liu $^{\mathrm{a}}$, Sophy J. Perdomo ${ }^{\mathrm{a}}$, Jaimie Ward ${ }^{\mathrm{a}}$, Eric D. Vidoni ${ }^{\mathrm{b}}$, Jason F. Sisante ${ }^{\mathrm{a}, \mathrm{c}}$, \\ Kiersten Kirkendoll ${ }^{\mathrm{a}}$, Jeffrey M. Burns ${ }^{\mathrm{b}}$ and Sandra A. Billinger ${ }^{\mathrm{a}, *}$ \\ ${ }^{a}$ Department of Physical Therapy and Rehabilitation Science, University of Kansas Medical Center, \\ Kansas City, KS, USA \\ ${ }^{\mathrm{b}}$ University of Kansas Alzheimer's Disease Center, Fairway, KS, USA \\ ${ }^{\mathrm{c}}$ Department of Physical Medicine and Rehabilitation, University of Kansas Medical Center, Kansas City, \\ $K S, U S A$
}

Handling Associate Editor: Jack de la Torre

Accepted 7 May 2019

\begin{abstract}
.
Background: Vascular health is closely related to Alzheimer's disease (AD). Vascular function measured by flow mediated dilation (FMD) or pulsatility index (PI) can be used as marker of peripheral and central vascular health but is poorly characterized in those at risk for AD.

Objective: To assess the relationship of peripheral and central vascular function with amyloid- $\beta$ (A $\beta$ ) and white matter lesion burden among cognitively normal older adults.

Methods: We enrolled participants 65 years of age and older. Using Doppler ultrasound, we assessed brachial artery FMD, and middle cerebral artery (PI). Global A $\beta$ burden, quantified using [18F] Florbetapir PET imaging, and white matter lesion volume (WML) were used as measures of AD pathology and vascular brain injury.

Results: After adjusting for age and cardiovascular risk factors, the data $(n=83)$ showed a negative association between FMD and $A \beta$ burden $(\beta=-0.03, p<0.001)$. FMD at a cut-off of $4.45 \%$ had $88 \%$ specificity and $75 \%$ sensitivity to elevated $\mathrm{A} \beta$ (AUC $=0.86,95 \% \mathrm{CI}: 0.77-0.95)$. FMD was not related to WML volume $(p=0.8)$, and PI was unrelated to A $\beta$ burden or WML volume $(0>0.4)$.

Conclusions: Among cognitively normal older adults, blunted peripheral vascular function, as measured by brachial artery FMD, is associated with $A \beta$ burden. These findings provide support for further exploration into the pathophysiological relationship of vascular health and $\mathrm{AD}$ risk as measured by $\mathrm{A} \beta$.
\end{abstract}

Keywords: Amyloid- $\beta$ protein, pulsatile flow, transcranial doppler sonography, vascular endothelium

\section{INTRODUCTION}

Although amyloid- $\beta(A \beta)$ accumulation is a hallmark of Alzheimer's disease (AD) pathology,

\footnotetext{
${ }^{*}$ Correspondence to: Sandra A. Billinger, PhD, Department of Physical Therapy and Rehabilitation Science, University of Kansas Medical Center, 3901 Rainbow Blvd, Mail Stop 2002, Kansas City, KS 66160, USA. Tel.: +1 913945 6685; Fax: +1 913588 9428; E-mail: sbillinger@kumc.edu.
}

increasing evidence indicates vascular health plays an important role in the development of AD [1-5]. People with AD have increased cerebral pulsatile flow, which can be measured as pulsatility index (PI) using transcranial Doppler ultrasound [6]. Higher PI measured in the middle cerebral artery (MCA) suggests increased resistance distal to the vessel being measured and can result in reduced cerebral blood flow and tissue damage [7]. Recently, individuals 
with a diagnosis of hypertension who demonstrated impaired cognition also demonstrated a significantly higher PI (above 1.1), while the group with hypertension and normal cognition had a lower PI (below 1.0). Higher PI is closely related to higher white matter lesion (WML) burden [8], a marker of small vessel ischemic disease associated with aging and cognitive decline [9-12]. Despite the current evidence, the relationship between PI with $A \beta$ burden in cognitively normal older adults is largely unknown.

Cardiovascular risk factors (e.g., hypertension, diabetes, hyperlipidemia) damage the endothelium leading to arterial stiffness and over time may reduce cerebral blood flow $[7,13]$. This vascular pathway may be synergistically contributing to the development of AD [13]. Peripheral vascular dysfunction, resulting from damage to the endothelium, could be the link between cardiovascular disease risk factors and $\mathrm{AD}[1,14,15]$ and may be the earliest event that triggers AD pathology $[14,16]$. For example, recent published work reported aortic stiffness (using cardiac magnetic resonance imaging technique) was related to lower whole brain cerebral blood flow in individuals $(n=155)$ without cognitive impairment [17] and highlights the importance maintaining vascular health in older adults. Therefore, identifying peripheral vascular systemic indicators would be advantageous.

Peripheral vascular dysfunction is considered to be an important contributor or event in the early stages of atherosclerosis and can be assessed using a technique called flow mediated dilation (FMD) typically in the brachial artery [18]. FMD is used as a biomarker of vascular disease [19] and has predictive value for future cardiovascular events [20]. Our prior work has shown that individuals with high cardiovascular risk (stroke, diabetes) and associated cardiovascular risk factors (hypertension, dyslipidemia) have lower brachial artery FMD values [21-23] than healthy individuals (low cardiovascular risk) due to deleterious effects on vascular function. Older adults with elevated $\mathrm{A} \beta$ (a risk factor for $\mathrm{AD}$ ) often have higher cardiovascular risk than those non-elevated $[21,24$, 25]. Therefore, linking peripheral vascular health via FMD to brain health could provide valuable information. Currently, there is a paucity of evidence as to whether older adults with elevated $A \beta$ have impaired peripheral vascular function. To bridge this gap in knowledge, we sought to evaluate the relationship of peripheral (FMD) and central (PI) vascular function with $A \beta$ and white matter lesion burden among cognitively normal older adults. Lower brachial artery
FMD is considered an indicator of peripheral vascular dysfunction $[18,20]$, while higher MCA PI is considered an indicator of vascular resistance in the smaller distal arteries [7]. Therefore, we expected that brachial artery FMD would be negatively associated with $\mathrm{A} \beta$ burden and WML burden. Conversely, we hypothesized that MCA PI would be positively associated with $A \beta$ and WML burden.

\section{METHODS}

\section{Participants}

We recruited individuals as part of an ongoing Alzheimer's and brain aging research program at the University of Kansas Alzheimer's Disease Center (KU ADC) to characterize cerebral A $\beta$ burden in cognitively normal older adults. For this study, the KU ADC recruited a convenience sample of individuals from the community who were interested in participating in brain aging research. Recruited individuals had no concomitant diagnosis of other neurologic conditions and no evidence of stroke or major head trauma on MRI. Inclusion criteria for the program were: 1) 65-90 years of age; 2) classified as cognitively normal/non-demented with a Clinical Dementia Rating $=0$ and no clinically significant evidence of stroke or deficits on neuropsychological testing (defined as no scores greater than 1.5 standard deviations below the mean on two or more tests in the National Alzheimer's Coordinating Center Uniform Data Set); 3) sedentary or underactive lifestyle defined as less than the recommended 150 min of moderate intensity exercise per week [26]; and 4) completion of [18F] Florbetapir positron emission tomography (PET) scan within 6 months of our experimental procedures. Exclusion criteria were: 1) Diagnostic and Statistical Manual of Mental Disorders-IV defined drug or alcohol abuse within the prior 2 years; 2) clinically significant depression or anxiety; 3) insulin-dependent diabetes; 4) myocardial infarction or symptoms of coronary artery disease within the prior 2 years; 5) acute decompensated congestive heart failure or class IV heart failure; 6) major orthopedic disability; and 7) inability to exercise due to pain or restrictions from physician.

The University of Kansas Medical Center Human Subjects Committee reviewed and approved the study. All participants provided institutionally approved written consent prior to study procedures. 


\section{Flow mediated dilation}

Brachial artery FMD is an assessment of endothelial-dependent function in response to reactive hyperemia [18]. FMD is calculated as the peak increase in arterial diameter from the baseline value in response to an acute increase in blood flow (reactive hyperemia) and expressed as percent change [27, 28]. We followed our previous published methods [21, 27, 29] and adhered to published recommendations for FMD [18]. Participants refrained from caffeinated beverages for $12 \mathrm{~h}$, physical activity for $24 \mathrm{~h}$, and fasted overnight. All morning medications for blood pressure were withheld [21]. All study procedures began between 7:30-9:00 am with FMD being conducted first. Participants rested in the supine position for $20 \mathrm{~min}$ in a quiet and dimly lit room. Room temperature was kept between $22-24^{\circ} \mathrm{C}$. HR was monitored continuously using $\mathrm{v} 5$ on the electrocardiogram

Images of the brachial artery were obtained with a 7.5 MHz linear array transducer (Siemens Medical Solutions, Malvern, PA). Once a satisfactory image of near and far arterial walls was obtained, the transducer was stabilized. Doppler flow angle was corrected at $60^{\circ}$. Baseline values for vessel diameter and blood velocity were recorded continuously for $1 \mathrm{~min}$. The automated cuff $($ SC5D $6 \times 83 \mathrm{~cm}$, D.E. Hokanson, Bellevue, Washington) with a rapid inflation system (D.E. Hokanson, Bellevue, Washington) was placed distal to the olecranon process and then inflated to $200 \mathrm{mmHg}$ and maintained for $5 \mathrm{~min}$. Diameter and blood velocity recordings resumed $20 \mathrm{~s}$ prior to cuff deflation and continued for $3 \mathrm{~min}$ post deflation. All images were stored on a computer and analyzed (Brachial Analyzer, Medical Imaging Applications, Coralville, Iowa).

\section{Transcranial doppler ultrasound}

After the FMD procedure, participants sat upright and were fitted with a head frame and TCD ultrasound $2 \mathrm{MHz}$ probe (RobotoC2MD, Multigon). If left MCA signal was not obtainable, the right side was used. Once the optimal signal was identified, recording commenced for $8 \mathrm{~min}$. Data were sampled at $500 \mathrm{~Hz}$. To analyze, the data were divided by R-to-R cardiac interval. For each cardiac cycle, systolic and diastolic velocities were identified, and the $\mathrm{MCAv}_{\text {mean }}$ was calculated as area under the curve $(\mathrm{cm} / \mathrm{s})$. The MCAv data were then interpolated to $0.5 \mathrm{~Hz}$ using shape-preserving, piecewise cubic interpolation. The PI was calculated as the differ- ence between MCA systolic and diastolic velocity divided by mean velocity for each cardiac cycle [30] during the $8 \mathrm{~min}$ data acquisition. Study personnel performing the TCD and FMD data collection were blinded to the $A \beta$ status of participants.

\section{[18F] Florbetapir PET and A $\beta$ burden analysis}

PET images were obtained on a GE Discovery ST16 PET/CT scanner. Two 5 min duration PET brain frames were acquired continuously, approximately $50 \mathrm{~min}$ after [18F] Florbetapir (370 MBq) administration. Head movement was minimized by use of self-adherent wrap across the forehead. PET frames were summed and attenuation corrected. To increase tissue uptake specificity, we calculated standardized uptake value ratios (SUVR) in several individualized regions using a custom processing pipeline in SPM12 (http://www.fil.ion.ucl.ac.uk/spm). First, the PET image was co-registered to the native T1weighted MRI (see next section). Next, we performed VBM8 unified segmentation and normalization of the anatomical T1-weighted MRI. Images were then smoothed using a $5 \times 5 \times 5 \mathrm{~mm}$ FWHM kernel. General regions of interest (ROI) from the Wake Forest Pick Atlas (anterior cingulate, posterior cingulate, precuneus, inferior medial frontal cortex, lateral temporal cortex, superior parietal cortex) were chosen for their relationship to $A \beta$ accumulation [31]. The general ROI were transformed to native anatomical space using the inverse parameters from the unified segmentation process, then crossed with each individual's gray matter probability map (threshold $>0.5$ ). The co-registered PET image was divided by the mean SUV of the whole cerebellum, creating an SUVR image. Mean SUVR in each individualized gray matter ROI was extracted. A global $\mathrm{A} \beta$ burden index was calculated as the mean of the 6 ROI. Individuals were classified as elevated if they had global $\mathrm{A} \beta$ burden $>1.1$ as this threshold has been associated with moderate-to-frequent neuritic plaques $[32,33]$.

\section{MRI and WML}

On a separate day, high-resolution MRI were acquired using a Siemens Skyra 3.0 Tesla scanner, including T1 (MP-RAGE; $1.0 * 1.0 * 1.2 \mathrm{~mm}$ voxels; TR $=2300 \mathrm{~ms}, \mathrm{TE}=2.98 \mathrm{~ms}, \mathrm{TI}=900 \mathrm{~ms}$, FOV $256 \mathrm{~mm}, 9^{\circ}$ flip angle) and T2-weighted images (FLAIR $0.9 * 0.9 * 5.0 \mathrm{~mm}$ voxels; TR: $9000 \mathrm{~ms}$, $\mathrm{TE}=91 \mathrm{~ms}, \mathrm{TI}=2500 \mathrm{~ms}$, FOV $240 \mathrm{~mm}, 150^{\circ}$ flip angle). We then used the Lesion Segment Tool, 
Version 2.0.13 [34], to generate total lesion volume maps. Briefly, the LST algorithm co-registered FLAIR images to the native space anatomical image. FLAIR intensity distribution was calculated for each tissue class, and these distributions were summed to create belief maps. Based on pilot work and visual inspection, as suggested by the developer, we selected an appropriate threshold, $k=0.125$, as the cutoff point on the gray matter belief map. This threshold was independently corroborated in a separate cohort on the same scanner (data not shown). The LST algorithm generates the white matter lesion segments and total lesion volume $(\mathrm{mL})$ and count based on the selected $k$ threshold [35]. Lesion volume (mL) was the primary WML burden measures used for analysis.

\section{Statistical analysis}

The data were analyzed using SPSS version 24.0 (SPSS Inc., Chicago, IL, USA). All data were tested for normal distribution using Shapiro-Wilk. Chisquare and Welch tests were used to analyze between group differences (A $\beta$ elevated, non-elevated) for categorical and continuous variables. If the data had skewed distribution, we used Mann-Whitney U tests. Multiple linear regression analyses were performed by making adjustment for participant age, sex, and a summed score of cardiovascular risk factors as defined by the American College of Sports Medicine (hypertension, family history of heart disease, obesity, sedentary lifestyle, age referenced to sex, diabetes, hyperlipidemia, and current smoking) [36] to determine the independent effect of FMD and PI on $A \beta$ burden. Continuous variables with normal distribution were expressed as the mean \pm standard deviation. $p$ values $<0.05$ were considered statistically significant. Previous work suggested that a FMD value below $5 \%$ is impaired and a marker of cardiovascular disease [37]. Therefore, we used receiver operating characteristic curves (ROC) to determine if a specific threshold of FMD would prove sensitive and specific for elevated $A \beta$ status.

\section{RESULTS}

\section{Participant characteristics}

Participants included 83 adults who had complete datasets for all outcome measures (MRI, PET, FMD, and TCD). The time between the PET scan and the subsequent experimental protocol for TCD and FMD was $58.3 \pm 43.1$ days. Those with elevated $\mathrm{A} \beta$ were older $(p=0.03)$ with no difference between cardiovascular risk factors (Table 1).

\section{Flow mediated dilation}

FMD was negatively associated with $\mathrm{A} \beta$ burden ( $\beta=-0.03, p<0.001)$ after adjusting for cardiovascu-

Table 1

Participant demographics

\begin{tabular}{|c|c|c|c|c|}
\hline & All cohort $n=83$ & $\mathrm{~A} \beta$ elevated $n=20$ & $\mathrm{~A} \beta$ non-elevated $n=63$ & $p$ \\
\hline Age, y & $71.1 \pm 5.2$ & $73.7 \pm 6.1$ & $70.3 \pm 4.6$ & 0.03 \\
\hline Female, $n(\%)$ & $56(67.5)$ & $14(70.0)$ & $42(66.7)$ & 0.78 \\
\hline Education, y & $16.7 \pm 2.7$ & $16.5 \pm 3.3$ & $16.8 \pm 2.5$ & 0.65 \\
\hline BMI, $\mathrm{kg} / \mathrm{m}^{2}$ & $26.7 \pm 4.0$ & $26.1 \pm 4.1$ & $26.8 \pm 4.0$ & 0.53 \\
\hline Systolic BP (mmHg) & $132.5 \pm 15.3$ & $135.0 \pm 16.5$ & $131.7 \pm 14.9$ & 0.41 \\
\hline Diastolic BP (mmHg) & $76.0 \pm 8.0$ & $75.5 \pm 6.8$ & $76.2 \pm 8.4$ & 0.73 \\
\hline Mean arterial $\mathrm{BP}(\mathrm{mmHg})$ & $73.8 \pm 11.6$ & $73.1 \pm 10.3$ & $74.0 \pm 12.0$ & 0.69 \\
\hline Total cholesterol (mmol/L) & $183.8 \pm 33.5$ & $172.6 \pm 27.9$ & $186.8 \pm 34.4$ & 0.13 \\
\hline Hypertension, $n(\%)$ & $31(37.3)$ & $10(50.0)$ & $21(33.3)$ & 0.18 \\
\hline Diabetes, $n(\%)$ & $3(3.6)$ & $1(5.0)$ & $2(3.2)$ & 0.70 \\
\hline CVD, $n(\%)$ & $5(6.0)$ & $3(15.0)$ & $2(3.2)$ & 0.05 \\
\hline Dyslipidemia, $n(\%)$ & $46(55.4)$ & $10(50.0)$ & $36(57.1)$ & 0.58 \\
\hline Smoking, $n(\%)$ & $2(2.4)$ & $0(0)$ & $2(3.2)$ & 0.42 \\
\hline ACE inhibitors, $n(\%)$ & $6(7.2)$ & $2(10.0)$ & $4(6.3)$ & 0.58 \\
\hline Calcium channel blocker, $n(\%)$ & $10(12.0)$ & $3(15.0)$ & $7(11.1)$ & 0.64 \\
\hline Beta blockers, $n(\%)$ & $12(14.5)$ & $5(25.0)$ & $7(11.1)$ & 0.12 \\
\hline Angiotensin II antagonist, $n(\%)$ & $10(12.0)$ & $3(15.0)$ & $7(11.1)$ & 0.64 \\
\hline Alpha adrenergic blocking, $n(\%)$ & $2(2.4)$ & $0(0)$ & $2(3.2)$ & 0.42 \\
\hline Antihyperlipidemic, $n(\%)$ & $39(47.0)$ & $12(60.0)$ & $27(42.9)$ & 0.18 \\
\hline Sex hormones, $n(\%)$ & $14(16.9)$ & $1(5.0)$ & $13(20.6)$ & 0.10 \\
\hline Thyroid, $n(\%)$ & $21(25.3)$ & $8(40.0)$ & $13(20.6)$ & 0.08 \\
\hline Bronchodialator, $n(\%)$ & $5(6.0)$ & $1(5.0)$ & $4(6.3)$ & 0.83 \\
\hline
\end{tabular}

$\mathrm{BMI}$, body mass index; $\mathrm{BP}$, blood pressure; $\mathrm{CVD}$, cardiovascular disease; $\mathrm{ACE}$, angiotension converting enzyme. 

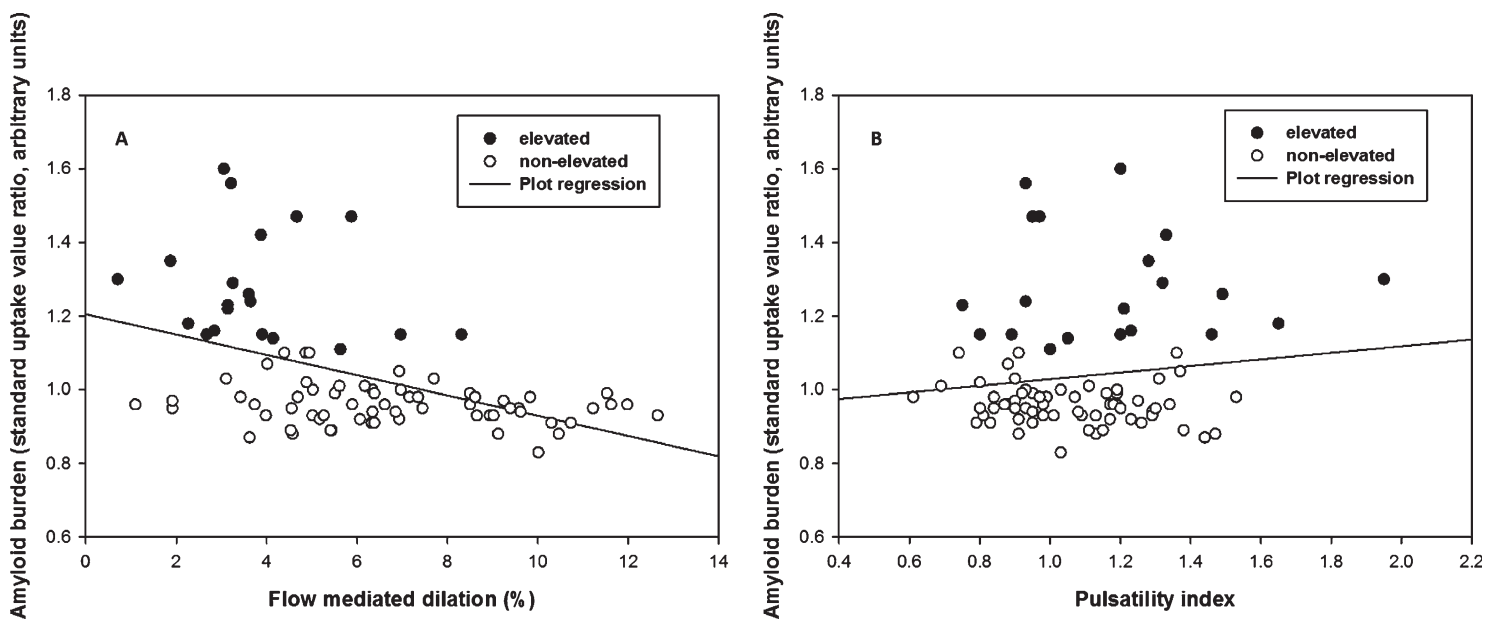

Fig. 1. Multiple linear regression of flow mediated dilation (FMD) and pulsatility index (PI) against A $\beta$ burden. A) There was a negative correlation between FMD and A $\beta$ burden across groups $(p<0.001, \beta=-0.03)$ after adjusting age, sex, and cardiovascular risk. $\mathrm{B})$ There was no significant correlation between PI and $\mathrm{A} \beta$ burden across groups $(p=0.415)$ after adjusting age, sex, and cardiovascular risk.

Table 2

Flow-mediated dilation between two groups

\begin{tabular}{lcccc}
\hline & All cohort $n=83$ & $\mathrm{~A} \beta$ elevated $n=20$ & $\mathrm{~A} \beta$ non-elevated $n=63$ & $p$ \\
\hline Baseline diameter (mm) & $3.7 \pm 0.6$ & $3.7 \pm 0.6$ & $3.7 \pm 0.6$ & 0.79 \\
Peak FMD (\%) & $6.1 \pm 2.8$ & $3.8 \pm 1.8$ & $6.8 \pm 2.7$ & $<0.01$ \\
Time to peak FMD (s) & $58.5 \pm 35.2$ & $72.1 \pm 36.4$ & $54.1 \pm 33.9$ & 0.05 \\
Peak Velocity (m/s) & $1.4 \pm 0.3$ & $1.4 \pm 0.2$ & $1.4 \pm 0.3$ & 0.21 \\
\hline
\end{tabular}

FMD, flow mediated dilation.

lar risk factor score and age, such that for every $1 \%$ FMD increase, the SUVR of A $\beta$ decreased by units of SUVR 0.03 (Fig. 1A). The FMD response was significantly lower in the elevated $\mathrm{A} \beta$ group (3.8\% versus $6.8 \%, p<0.01)$ and time to peak FMD was slower in the elevated $\mathrm{A} \beta$ group $(p=0.05)$. Peak velocity was not different (Table 2). By ROC analysis, an FMD of $4.45 \%$ had $88 \%$ specificity and $75 \%$ sensitivity to elevated $\mathrm{A} \beta$ ( $\mathrm{AUC}=0.86$, 95\% CI: $0.77-0.95$ ) (Fig. 2). FMD was not associated with WML volume, $p=0.83$.

\section{Pulsatility index}

PI was not associated with $\mathrm{A} \beta$ burden $(p=0.67$, Fig. $1 \mathrm{~B})$ or WML volume $(p=0.42)$. PI was not significantly different between $\mathrm{A} \beta$ groups, $(1.18$ versuss $1.06, p=0.14$ ) (Table 3).

\section{DISCUSSION}

The main finding of this study revealed impaired brachial artery FMD was significantly associated with increased $A \beta$ burden among cognitively normal older adults. For every $1 \%$ FMD increase, the
FMD is a sensitive and specific predictor of elevated $A \beta$

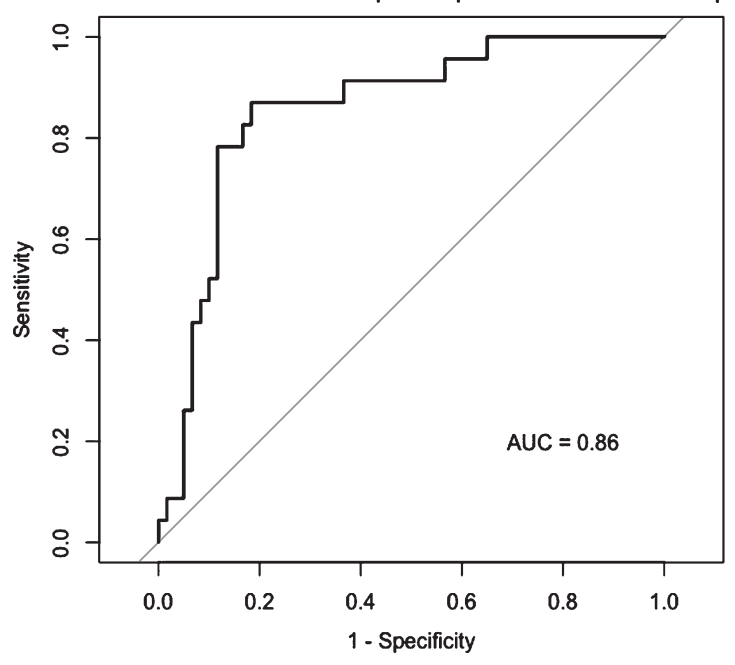

Fig. 2. FMD is a sensitive and specific predictor of elevated $A \beta$. By ROC analysis, the optimal cut point of FMD associated with elevated $A \beta$ was $4.45 \%$, with $88 \%$ specificity and $75 \%$ sensitivity to elevated $\mathrm{A} \beta$ ( $\mathrm{AUC}=0.86,95 \% \mathrm{CI}: 0.77-0.95$ ).

A $\beta$ SUVR decreased by 0.3 independent of age and vascular disease risks. A $1 \%$ decrease in FMD is meaningful given that after the 4th and 5th decade 
Table 3

Vascular parameters and WML burden

\begin{tabular}{lcccc}
\hline & All cohort $(n=83)$ & $\mathrm{A} \beta$ elevated $(n=20)$ & $\mathrm{A} \beta$ non-elevated $(n=63)$ & $p$ \\
\hline PI of MCA & $1.09 \pm 0.24$ & $1.18 \pm 0.30$ & $1.06 \pm 0.21$ & 0.11 \\
WML volume $(\mathrm{mL})$ & $3.3 \pm 3.8$ & $3.7 \pm 4.0$ & $3.2 \pm 3.7$ & 0.47 \\
WML number & $16.0 \pm 7.5$ & $17.3 \pm 6.8$ & $15.6 \pm 7.8$ & 0.22 \\
\hline
\end{tabular}

PI, pulsatility index; WML, white matter lesion.

of life, FMD has been reported to decrease by $0.21-0.49 \%$ with each additional year of normal aging [38]. Additionally, we found that an FMD of $4.45 \%$ was sensitive and specific to $A \beta$ elevation. This value is close to the 5\% FMD threshold, which is used as the biomarker for cardiovascular disease. Our data suggests that peripheral vascular function is concomitantly impaired with higher brain $A \beta$ accumulation.

There is some existing evidence that brachial artery FMD is impaired in those with AD. One study compared 25 patients with $\mathrm{AD}$ and 24 older adult control participants [39]. Individuals enrolled were free of cardiometabolic disease, hypertension, and stroke, and were not taking medications that affected arterial vasodilation. Their results showed significantly impaired FMD in AD patients compared to controls (3.4\% versus $8.4 \%, p<0.01)$. The authors concluded that peripheral vascular dysfunction exists in those with AD without existing cardiovascular disease and associated risk factors further supporting that $\mathrm{AD}$ may be a "consequence of poor vascular pathology" [39] such as endothelial dysfunction. Further, these findings were independent of age and an inverse relationship between FMD and stage of AD using the Clinical Dementia Rating scale.

In the present study, our findings support and extend previous work to include peripheral vascular dysfunction in cognitively normal individuals with and without elevated $A \beta$. We found those with the elevated $A \beta$ (highest risk for $A D$ ) had significantly attenuated FMD when compared to the non-elevated group $(3.8 \%$ versus $6.8 \%, p<0.01)$. Although our FMD results are similar to prior work,[39] our participants presented with existing cardiovascular disease and associated risk factors, which integrate the role of lifestyle and vascular health.

Globally, there is increasing interest in the role of lifestyle factors (physical activity) and vascular health (blood pressure) to promote healthy brain aging [40]. This topic is of interest since injury to cerebral blood vessels including cerebral vessel pathology over the lifespan negatively affects the blood brain barrier and can increase inflammation [41]. Over time, blood brain barrier dysfunction and the alteration of neurovascular function such as cerebral endothelial dysfunction may accelerate $\mathrm{A} \beta$ accumulation by reducing perivascular clearance from the brain $[41,42]$. The role of a healthy cerebrovascular system is essential to $A \beta$ clearance. Reports suggest that the cerebrovascular system clears $\sim 80-85 \%$ of $A \beta$ peptides and that damage to brain endothelial cells particularly at the capillary level results in a loss of key clearance $A \beta$ receptors such as p-glycoprotein and lipoprotein receptorrelated protein 1 , which leads to $A \beta$ accumulation in the brain and further cerebrovascular impairment [41, 43-45].

Our previous work suggests in older cognitively intact adults with varying $A \beta$ levels, a negative inverse relationship exists between cerebrovascular response during exercise and global $A \beta$ burden, which may suggest cerebrovascular impairment is present before changes in cognition [46]. However, we only studied middle cerebral artery velocity and not other measures of cerebrovascular impairment such as PI. A higher PI has been reported in most of intracranial arteries in those with cognitive impairment [7] and AD [47, 48] when compared to nondemented individuals. In our study, PI was not associated with global $A \beta$ burden and PI was not significantly different in those with elevated $A \beta$. A potential explanation may be that PI was not sensitive to detect differences in those in the earliest stages of pathology or the number of individuals with highest global A $\beta$ burden was too small. We further acknowledge that our overall sample size was small and more individuals were characterized as non-elevated $(n=63)$ compared to those with elevated $\mathrm{A} \beta(n=20)$.

Aging and arterial stiffness of the cerebral vessels can lead to increased PI and result in WML $[8,49,50]$ especially with increased duration (in years) of hypertension [7]. The possibility exists that the individuals in this present study had experienced hypertension for a shorter duration of time or were well-controlled by medication resulting in no differences for PI and WML burden, which could be influenced by the presence of higher education and lack of racial diversity in our sample of participants. This topic warrants further exploration. 
Our study has several strengths. First, our participants were well characterized as cognitively normal older adults, and we used PET imaging for to quantify global $\mathrm{A} \beta$ burden. Second, we used a gold standard measurement (FMD) for peripheral vascular function and used a rigorous, well-controlled FMD protocol that followed the published recommendations [18]. FMD has the advantage of being noninvasive and feasible in clinical ultrasound settings. Additionally, study personnel who conducted FMD and TCD measurements were blinded to $A \beta$ status. In our analyses, we controlled for potential confounders including age, sex, and cardiovascular disease. As reported previously, advancing age may influence peripheral vascular function and is an important factor to control in data analysis [39].

Despite these strengths, our study has limitations that should be considered. Although these data are cross sectional, the possibility exists that higher $A \beta$ burden may be a downstream consequence of poor vascular health. Future research should target middle age cohorts free of cognitive impairment and assess vascular health with longitudinal follow up. This would allow for a more robust assessment of vascular health and whether the result in $A \beta$ accumulation over time exists. Second, our conclusions are limited by the homogeneity of our sample which was predominantly white, educated, cognitively typical and free of severe large vascular disease, stroke, transient ischemic attack, or traumatic brain injury. Third, we were unable to evaluate the importance of genetic risk factors such as the APOE4 allele, the strongest genetic risk factor for late-onset, sporadic AD [51]. APOE4 carriers demonstrate more evidence of neurovascular insult such as white matter hyperintensities and microbleeds than non-carriers [52]. APOE appears key to maintaining cerebrovascular integrity independent of $A \beta$ deposition [53], and the APOE4 allele may accelerate blood-brain barrier degradation [54]. Future work in this area should look at the role of APOE4 and other genetic factors on both central and peripheral vascular function.

\section{Conclusions}

In conclusion, the present study provides support that impaired peripheral vascular function was significantly associated with increased $A \beta$ burden. Those with lower FMD are more likely to have elevated $A \beta$ than those considered non-elevated. These findings provide further support for the important role of vascular health in older adults, and the need for additional exploration of the pathophysiological relationship of vascular health and $A \beta$ accumulation.

\section{ACKNOWLEDGMENTS}

We would like to thank Torrie Cross (University of Kansas), Kelsy Schoen (University of Kansas Medical Center), Andrea Sander (University of Kansas Medical Center), and Dana Stumpff (University of Kansas Medical Center) for their help in data collection. We would also like to thank Allegra Morton (University of Kansas Medical Center) and Carolyn Kaufman (University of Kansas Medical Center) for their assistance with organizing data and tables. This study was funded in part by K01HD067318 from the Eunice Kennedy Shriver National Institute of Child Health and Human Development (Dr. Billinger) and by the American Heart Association Grant 16GRNT30450008 (Dr. Billinger). Dr. Sisante was supported in part by T32HD057850 from the Eunice Kennedy Shriver National Institute of Child Health and Human Development. This project was supported by the University of Kansas Alzheimer's Disease Center (P30 AG035982) and by an Institutional Clinical and Translational Science Award, NIH/NCATS Grant Number UL1TR000001. Avid Radiopharmaceutical, Eli Lilly and Co., and the NIA (R01 AG043962) provided funds that supported the florbetapir imaging procedure. Its contents are solely the responsibility of the authors and do not necessarily represent the official views of the NIH or other funding agencies. Dr. Billinger receives support from the Wohlgemuth Faculty Scholar Award. The Georgia Holland Research in Exercise and Cardiovascular Health (REACH) laboratory space was supported by the Georgia Holland Endowment Fund.

Authors' disclosures available online (https:// www.j-alz.com/manuscript-disclosures/18-1268r2).

\section{REFERENCES}

[1] Girouard H, Iadecola C (2006) Neurovascular coupling in the normal brain and in hypertension, stroke, and Alzheimer disease. J Appl Physiol (1985) 100, 328-335.

[2] Arvanitakis Z, Capuano AW, Lamar M, Shah RC, Barnes LL, Bennett DA, Schneider JA (2018) Late-life blood pressure association with cerebrovascular and Alzheimer disease pathology. Neurology 91, e517-e525.

[3] Gottesman RF, Schneider AL, Zhou Y, Coresh J, Green E, Gupta N, Knopman DS, Mintz A, Rahmim A, Sharrett AR, Wagenknecht LE, Wong DF, Mosley TH (2017) Association between midlife vascular risk factors and estimated brain amyloid deposition. JAMA 317, 1443-1450. 
[4] Rabin JS, Yang HS, Schultz AP, Hanseeuw BJ, Hedden T, Viswanathan A, Gatchel JR, Marshall GA, Kilpatrick E, Klein H, Rao V, Buckley RF, Yau WW, Kirn DR, Rentz DM, Johnson KA, Sperling RA, Chhatwal JP (2019) Vascular risk and beta-amyloid are synergistically associated with cortical tau. Ann Neurol 85, 272-279.

[5] Iadecola C (2016) Vascular and metabolic factors in Alzheimer's disease and related dementias: Introduction. Cell Mol Neurobiol 36, 151-154.

[6] Rivera-Rivera LA, Turski P, Johnson KM, Hoffman C, Berman SE, Kilgas P, Rowley HA, Carlsson CM, Johnson SC, Wieben O (2016) 4D flow MRI for intracranial hemodynamics assessment in Alzheimer's disease. J Cereb Blood Flow Metab 36, 1718-1730.

[7] Harris S, Reyhan T, Ramli Y, Prihartono J, Kurniawan M (2018) Middle cerebral artery pulsatility index as predictor of cognitive impairment in hypertensive patients. Front Neurol 9, 538

[8] Mitsumura H, Miyagawa S, Komatsu T, Sakamoto Y, Kono Y, Furuhata H, Iguchi Y (2015) Transcranial color flow imaging can evaluate the severity of periventricular hyperintensity. J Stroke Cerebrovasc Dis 24, 112-116.

[9] Wardlaw JM, Hernández MCV, Muñoz-Maniega S (2015) What are white matter hyperintensities made of? Relevance to vascular cognitive impairment. J Am Heart Assoc 4, e001140.

[10] van den Berg E, Geerlings MI, Biessels GJ, Nederkoorn PJ, Kloppenborg RP (2018) White matter hyperintensities and cognition in mild cognitive impairment and Alzheimer's disease: A domain-specific meta-analysis. J Alzheimers Dis 63, 515-527.

[11] Prins ND, Scheltens P (2015) White matter hyperintensities, cognitive impairment and dementia: An update. Nat Rev Neurol 11, 157-165.

[12] Habes M, Erus G, Toledo JB, Zhang T, Bryan N, Launer LJ, Rosseel Y, Janowitz D, Doshi J, Van der Auwera S, von Sarnowski B, Hegenscheid K, Hosten N, Homuth G, Volzke H, Schminke U, Hoffmann W, Grabe HJ, Davatzikos C (2016) White matter hyperintensities and imaging patterns of brain ageing in the general population. Brain 139, 1164-1179.

[13] Viswanathan A, Rocca WA, Tzourio C (2009) Vascular risk factors and dementia: How to move forward? Neurology 72 , 368-374.

[14] Farkas E, Luiten PG (2001) Cerebral microvascular pathology in aging and Alzheimer's disease. Prog Neurobiol 64, 575-611.

[15] Ostergaard L, Aamand R, Gutierrez-Jimenez E, Ho YC, Blicher JU, Madsen SM, Nagenthiraja K, Dalby RB, Drasbek KR, Moller A, Braendgaard H, Mouridsen K, Jespersen SN, Jensen MS, West MJ (2013) The capillary dysfunction hypothesis of Alzheimer's disease. Neurobiol Aging 34, 1018-1031.

[16] Agyare EK, Leonard SR, Curran GL, Yu CC, Lowe VJ, Paravastu AK, Poduslo JF, Kandimalla KK (2013) Traffic jam at the blood-brain barrier promotes greater accumulation of Alzheimer's disease amyloid- $\beta$ proteins in the cerebral vasculature. Mol Pharm 10, 1557-1565.

[17] Jefferson AL, Cambronero FE, Liu D, Moore EE, Neal JE, Terry JG, Nair S, Pechman KR, Rane S, Davis LT (2018) Higher aortic stiffness is related to lower cerebral blood flow and preserved cerebrovascular reactivity in older adults. Circulation 138, 1951-1962.

[18] Thijssen DH, Black MA, Pyke KE, Padilla J, Atkinson G, Harris RA, Parker B, Widlansky ME, Tschakovsky ME,
Green DJ (2011) Assessment of flow-mediated dilation in humans: A methodological and physiological guideline. $\mathrm{Am}$ J Physiol Heart Circ Physiol 300, H2-12.

[19] Verma S, Buchanan MR, Anderson TJ (2003) Endothelial function testing as a biomarker of vascular disease. Circulation 108, 2054-2059.

[20] Inaba Y, Chen JA, Bergmann SR (2010) Prediction of future cardiovascular outcomes by flow-mediated vasodilatation of brachial artery: A meta-analysis. Int J Cardiovasc Imaging 26, 631-640.

[21] Billinger SA, Sisante JV, Mattlage AE, Alqahtani AS, Abraham MG, Rymer MM, Camarata PJ (2017) The relationship of pro-inflammatory markers to vascular endothelial function after acute stroke. Int J Neurosci 127, 486-492.

[22] Billinger SA, Sisante JV, Whitaker AA, Abraham MG (2018) Time course of flow-mediated dilation and vascular endothelial growth factor following acute stroke. J Stroke Cerebrovasc Dis 27, 957-962.

[23] Billinger SA, Sisante JV, Alqahtani AS, Pasnoor M, Kluding PM (2017) Aerobic exercise improves measures of vascular health in diabetic peripheral neuropathy. Int J Neurosci 127, 80-85.

[24] Femminella GD, Taylor-Davies G, Scott J, Edison P, Alzheimer's Disease Neuroimaging Initiative (2018) Do cardiometabolic risk factors influence amyloid, tau, and neuronal function in APOE4 carriers and non-carriers in Alzheimer's disease trajectory? J Alzheimers Dis 64, 981993.

[25] Toledo JB, Toledo E, Weiner MW, Jack CR, Jr., Jagust W, Lee VM, Shaw LM, Trojanowski JQ, Alzheimer's Disease Neuroimaging Initiative (2012) Cardiovascular risk factors, cortisol, and amyloid-beta deposition in Alzheimer's Disease Neuroimaging Initiative. Alzheimers Dement 8, 483-489.

[26] Committee PAGA (2008) Physical activity guidelines advisory committee report, 2008. US Department of Health and Human Services, Washington, DC, A1-H14.

[27] Billinger SA, Mattlage AE, Ashenden AL, Lentz AA, Harter G, Rippee MA (2012) Aerobic exercise in subacute stroke improves cardiovascular health and physical performance. J Neurol Phys Ther 36, 159-165.

[28] Padilla J, Johnson BD, Newcomer SC, Wilhite DP, Mickleborough TD, Fly AD, Mather KJ, Wallace JP (2009) Adjusting flow-mediated dilation for shear stress stimulus allows demonstration of endothelial dysfunction in a population with moderate cardiovascular risk. $J$ Vasc Res $\mathbf{4 6}$, 592-600.

[29] Kluding PM, Pasnoor M, Singh R, D'Silva LJ, Yoo M, Billinger SA, LeMaster JW, Dimachkie MM, Herbelin L, Wright DE (2015) Safety of aerobic exercise in people with diabetic peripheral neuropathy: Single-group clinical trial. Phys Ther 95, 223-234.

[30] de Riva N, Budohoski KP, Smielewski P, Kasprowicz M, Zweifel C, Steiner LA, Reinhard M, Fábregas N, Pickard JD, Czosnyka M (2012) Transcranial Doppler pulsatility index: What it is and what it isn't. Neurocrit Care 17, 58-66.

[31] Joshi AD, Pontecorvo MJ, Clark CM, Carpenter AP, Jennings DL, Sadowsky CH, Adler LP, Kovnat KD, Seibyl JP, Arora A, Saha K, Burns JD, Lowrey MJ, Mintun MA, Skovronsky DM, Florbetapir F 18 Study Investigators (2012) Performance characteristics of amyloid PET with florbetapir F 18 in patients with alzheimer's disease and cognitively normal subjects. J Nucl Med 53, 378-384.

[32] Clark CM, Pontecorvo MJ, Beach TG, Bedell BJ, Coleman RE, Doraiswamy PM, Fleisher AS, Reiman EM, Sabbagh 
MN, Sadowsky CH, Schneider JA, Arora A, Carpenter AP, Flitter ML, Joshi AD, Krautkramer MJ, Lu M, Mintun MA, Skovronsky DM, AV-45-A16 Study Group (2012) Cerebral PET with florbetapir compared with neuropathology at autopsy for detection of neuritic amyloid-beta plaques: A prospective cohort study. Lancet Neurol 11, 669-678.

[33] Joshi AD, Pontecorvo MJ, Lu M, Skovronsky DM, Mintun MA, Devous MD Sr (2015) A semiautomated method for quantification of F 18 Florbetapir PET images. J Nucl Med 56, 1736-1741.

[34] Schmidt P, Gaser C, Arsic M, Buck D, Forschler A, Berthele A, Hoshi M, Ilg R, Schmid VJ, Zimmer C, Hemmer B, Muhlau M (2012) An automated tool for detection of FLAIR-hyperintense white-matter lesions in multiple sclerosis. Neuroimage 59, 3774-3783.

[35] Maldjian JA, Whitlow CT, Saha BN, Kota G, Vandergriff C, Davenport EM, Divers J, Freedman BI, Bowden DW (2013) Automated white matter total lesion volume segmentation in diabetes. AJNR Am J Neuroradiol 34, 2265-2270.

[36] Pescaltello L, Arena R, Riebe D, Thompson PD (2014) ACSM's Guidelines for Exercise Testing and Prescription, 9th edition. Wolters Kluwer/Lippincott Williams \& Wilkins, Philadelphia, PA.

[37] Dalli E, Segarra L, Ruvira J, Esteban E, Cabrera A, Lliso R, Lopez E, Llopis E, Sotillo JF (2002) Brachial artery flowmediated dilation in healthy men, men with risk factors, and men with acute myocardial infarction. Importance of occlusion-cuff position. Rev Esp Cardiol 55, 928-935.

[38] Celermajer DS, Sorensen KE, Spiegelhalter DJ, Georgakopoulos D, Robinson J, Deanfield JE (1994) Aging is associated with endothelial dysfunction in healthy men years before the age-related decline in women. $J$ Am Coll Cardiol 24, 471-476.

[39] Dede DS, Yavuz B, Yavuz BB, Cankurtaran M, Halil M, Ulger Z, Cankurtaran ES, Aytemir K, Kabakci G, Ariogul S (2007) Assessment of endothelial function in Alzheimer's disease: Is Alzheimer's disease a vascular disease? $J$ Am Geriatr Soc 55, 1613-1617.

[40] Gorelick PB, Furie KL, Iadecola C, Smith EE, Waddy SP, Lloyd-Jones DM, Bae HJ, Bauman MA, Dichgans M, Duncan PW, Girgus M, Howard VJ, Lazar RM, Seshadri S, Testai FD, van Gaal S, Yaffe K, Wasiak H, Zerna C; American Heart Association/American Stroke Association (2017) Defining optimal brain health in adults: A presidential advisory from the American Heart Association/American Stroke Association. Stroke 48, e284-e303.

[41] Sweeney MD, Sagare AP, Zlokovic BV (2018) Blood-brain barrier breakdown in Alzheimer disease and other neurodegenerative disorders. Nat Rev Neurol 14, 133-150.

[42] Iadecola C (2013) The pathobiology of vascular dementia. Neuron 80, 844-866.

[43] Sagare AP, Bell RD, Zlokovic BV (2013) Neurovascular defects and faulty amyloid-beta vascular clearance in Alzheimer's disease. J Alzheimers Dis 33(Suppl 1), S87S100.
[44] Nelson AR, Sagare AP, Zlokovic BV (2017) Role of clusterin in the brain vascular clearance of amyloid-beta. Proc Natl Acad Sci U S A 114, 8681-8682.

[45] Shibata M, Yamada S, Kumar SR, Calero M, Bading J, Frangione B, Holtzman DM, Miller CA, Strickland DK, Ghiso J, Zlokovic BV (2000) Clearance of Alzheimer's amyloid- $\beta(1-40)$ peptide from brain by LDL receptorrelated protein-1 at the blood-brain barrier. $J$ Clin Invest 106, 1489-1499.

[46] Sisante JV, Vidoni ED, Kirkendoll K, Ward J, Liu Y, Kwapiszeski S, Maletsky R, Burns JM, Billinger SA (2019) Blunted cerebrovascular response is associated with elevated beta-amyloid. J Cereb Blood Flow Metab 39, 89-96.

[47] Roher AE, Garami Z, Tyas SL, Maarouf CL, Kokjohn TA, Belohlavek M, Vedders LJ, Connor D, Sabbagh MN, Beach TG (2011) Transcranial Doppler ultrasound blood flow velocity and pulsatility index as systemic indicators for Alzheimer's disease. Alzheimers Dement 7, 445-455.

[48] Alwatban M, Murman DL, Bashford G (2019) Cerebrovascular reactivity impairment in preclinical Alzheimer's disease. J Neuroimaging. doi: 10.1111/jon.12606

[49] Fu JH, Lu CZ, Hong Z, Dong Q, Ding D, Wong KS (2006) Relationship between cerebral vasomotor reactivity and white matter lesions in elderly subjects without large artery occlusive disease. J Neuroimaging 16, 120-125.

[50] Rodriguez I, Lema I, Blanco M, Rodriguez-Yanez M, Leira R, Castillo J (2010) Vascular retinal, neuroimaging and ultrasonographic markers of lacunar infarcts. Int J Stroke 5, 360-366.

[51] Bertram L, McQueen MB, Mullin K, Blacker D, Tanzi RE (2007) Systematic meta-analyses of Alzheimer disease genetic association studies: The AlzGene database. Nat Genet 39, 17-23.

[52] Schilling S, DeStefano AL, Sachdev PS, Choi SH, Mather KA, DeCarli CD, Wen W, Hogh P, Raz N, Au R, Beiser A, Wolf PA, Romero JR, Zhu YC, Lunetta KL, Farrer L, Dufouil C, Kuller LH, Mazoyer B, Seshadri S, Tzourio C, Debette S (2013) APOE genotype and MRI markers of cerebrovascular disease: Systematic review and meta-analysis. Neurology 81, 292-300.

[53] Bell RD, Winkler EA, Singh I, Sagare AP, Deane R, Wu Z, Holtzman DM, Betsholtz C, Armulik A, Sallstrom J, Berk BC, Zlokovic BV (2012) Apolipoprotein E controls cerebrovascular integrity via cyclophilin A. Nature $\mathbf{4 8 5}$, 512-516.

[54] Halliday MR, Rege SV, Ma Q, Zhao Z, Miller CA, Winkler EA, Zlokovic BV (2016) Accelerated pericyte degeneration and blood-brain barrier breakdown in apolipoprotein E4 carriers with Alzheimer's disease. J Cereb Blood Flow Metab 36, 216-227. 